Article

\title{
Identification of the Appropriate Boundary Size to Use When Measuring the Food Retail Environment Surrounding Schools
}

\author{
Laura Seliske ${ }^{1}$, William Pickett ${ }^{1,2}$, Andrei Rosu ${ }^{3}$ and Ian Janssen ${ }^{1,3, *}$ \\ 1 Department of Community Health and Epidemiology, Queen's University, Kingston, ON K7L 3N6, \\ Canada; E-Mails: 1seliske@gmail.com (L.S.); will.pickett@queensu.ca (W.P.) \\ 2 Clinical Research Center, Angada 3, Kingston General Hospital, 76 Stuart St., Kingston, \\ ON K7L 2V7, Canada \\ 3 School of Kinesiology and Health Studies, Queen's University, 28 Division St., Kingston, \\ ON K7L 3N6, Canada; E-Mail: rosua@queensu.ca (A.R.) \\ * Author to whom correspondence should be addressed; E-Mail: ian.janssen@queensu.ca; \\ Tel.: +1-613-533-6000 (ext. 78631); Fax: +1-613-533-2009.
}

Received: 17 May 2012; in revised form: 12 June 2012 / Accepted: 24 July 2012 /

Published: 31 July 2012

Abstract: This study included 6,971 students in grades 9 and 10 (ages 13 to 16 years) from 158 schools who participated in the 2009/2010 Health Behaviour in School-aged Children Study. Students provided information on where they typically ate lunch. The number of food retailers was obtained for six road network buffer sizes $(500,750,1,000$, 1,500, 2,000, and 5,000 meters) surrounding schools. Associations between the presence of food retailers near schools and students' lunchtime eating behaviours were examined using multilevel logistic regression. Comparisons of model fit statistics indicated that the $1,000 \mathrm{~m}$ buffer provided the best fit. At this distance, students with $\geq 3$ food retailers near their schools had a 3.42 times greater relative odds (95\% CI: 2.12-5.52) of eating their lunchtime meal at a food retailer compared to students with no nearby food retailers. Students who had $\geq 2$ food retailers within $750 \mathrm{~m}$ of their schools had a 2.74 times greater relative odds (95\% CI: $1.75-4.29$ ), while those who had $\geq 1$ food retailer within $500 \mathrm{~m}$ of their schools had 2.27 times greater relative odds of eating at food retailer $(95 \% \mathrm{CI}$ : 1.46-3.52) compared to those with no nearby food retailers. For distances greater than $1,000 \mathrm{~m}$, no consistent relationships were found. 
Keywords: built environment; youth; schools; geographic information systems

\section{Introduction}

Over the past three decades, the prevalence of obesity among youth has increased dramatically worldwide [1]. There has been a lack of long-term success in its prevention via interventions that focus solely on individual-level factors [2]. This has resulted in the adoption of a more comprehensive understanding of its determinants, which include the influence of the food retail environment on eating behaviours in young people [3]. The food retail environment refers to the availability of food retailers such as fast food restaurants and convenience stores. In general, foods sold at these retailers are of poor nutritional quality [4-6] and excess consumption is associated with adverse health outcomes such as obesity and cardiometabolic diseases [7-10]. For young people, the food retail environment includes food retailers surrounding their homes and schools [11,12]. Relationships between the food retail environment and students' lunchtime eating behaviours [13] and obesity [14-16] have been found.

The food retail environment has been measured using both subjective [17,18] and objective [19,20] methods. Subjective measures rely on perceptions about the self-reported availability of nearby food retailers, while objective measures use geographic information systems (GIS) software to map food retailers within a given geographic area. Due to the poor correlation between subjective and objective measures of the food retail environment [21], objective GIS-based measures are preferred. GIS-based studies have used a variety of boundary types to capture the food retail environment, including census boundaries [22], ZIP codes [16], circular buffers [14], and road network buffers [20]. A limitation of census and ZIP code boundaries are that they were designed for administrative purposes and vary in size. Circular buffers overcome this limitation, but do not reflect how people travel from one location to another. Furthermore, road network-based food retailer measures are more strongly related to young peoples' eating behaviours compared to circular buffer based measures [13].

Recent literature reviews have identified the selection of the appropriate buffer size as a key methodological issue for studies of the food retail environment [3,23]. Some studies have addressed this by using various buffer sizes [14,20,24,25]. Davis and Carpenter [14] found that chain fast food restaurants within 0 to $400 \mathrm{~m}$ and $400 \mathrm{~m}$ to $800 \mathrm{~m}$ of schools, but not $800 \mathrm{~m}$ to $1,200 \mathrm{~m}$, were associated with students' body mass index (BMI) values. Laska et al., [24] found that food retailers within $1,600 \mathrm{~m}$ of homes, but not $800 \mathrm{~m}$ or $3,000 \mathrm{~m}$, were associated with adolescents' sugar sweetened beverage intake and obesity. However, none of the studies conducted a formal analysis to identify which buffer size was the best predictor of eating behaviours or obesity. Furthermore, some studies only used two buffer sizes [20,24,25], which may have resulted in the most appropriate buffer size being excluded. Finally, some studies took place within a single city [24,25] or state [14,20], limiting their representativeness.

The primary objective of this study was to identify the most appropriate buffer size to use when studying the relationship between the school food retail environment and the eating behaviours of Canadian students. To achieve this, the food retail environment surrounding schools was measured using several buffer sizes. Multilevel logistic regression was used to examine associations between the 
number of food retailers in each buffer size and students' lunchtime eating behaviours. Model fit statistics were used to determine the most appropriate buffer size.

\section{Experimental Section}

\subsection{Overview of Study Design}

This was a multilevel cross-sectional analysis of schools participating in the 2009/2010 Canadian Health Behaviour in School-aged Children (HBSC) study. Addresses of food retailers near schools were obtained using an online food retailer database. The number of food retailers surrounding each school was obtained for the following road network-based buffers: $500 \mathrm{~m}, 750 \mathrm{~m}, 1,000 \mathrm{~m}, 1,500 \mathrm{~m}$, $2,000 \mathrm{~m}$ and $5,000 \mathrm{~m}$. Associations between the presence of food retailers and students' reports of eating their lunch at a food retailer were then assessed.

\subsection{Study Sample}

The 2009/2010 Canadian HBSC study involved a survey of students from 436 schools and collected information on a variety of health behaviours in students in grades 6 to 10 (approximate ages 11-16 years). Classes were the primary sampling unit, and they were stratified by province, with an oversampling of some provinces and the three northern territories. Two Canadian provinces with small populations (New Brunswick and Prince Edward Island) were unable to participate in the 2009/2010 survey. The HBSC also excludes students in private schools, incarcerated youth, special needs schools and students who are home schooled. Ethics approval was obtained from the Queen's University Health Sciences Research Ethics Board. Subject consent was obtained at the school board and school levels as well as from parents or guardians (either explicitly or implicitly, as determined by school board policy).

In the current analysis, the sample was restricted to the 169 schools where students were permitted to leave school grounds, making it possible for them to access nearby food retailers. Because only $1.1 \%$ of grade 6 to 8 students reported the study outcome, they were excluded from the analysis. Due to missing information on food sources within schools or in the school neighbourhoods, a further 11 schools were excluded. Finally, 940 students were excluded because of missing data on key variables. The final analyses involved 6,971 students from 158 schools.

\subsection{School Food Retail Environment}

The addresses of the 158 eligible HBSC schools were mapped in ArcGIS (ESRI, version 9.3) and road network-based buffers were constructed using the following distances: $500 \mathrm{~m}, 750 \mathrm{~m}, 1,000 \mathrm{~m}, 1,500 \mathrm{~m}$, 2,000 $\mathrm{m}$ and 5,000 $\mathrm{m}$. These distances were selected based upon existing precedents [19,20,26-28]. Road network-based buffers were chosen instead of circular buffers because they are a better measure of the food retail environment surrounding schools [13]. The buffers were created using a road network database provided by CanMaps Streetfiles (DMTI Spatial Inc., v.2009.4, Markham ON, Canada). Roads extending outwards from the schools were followed until they reached their specified endpoint. Lines connecting the endpoints were used to create the border of the road network-based buffers. Figure 1 provides an illustration of the multiple road network buffers used in this study. 
Figure 1. The school is in the centre of the figure and is surrounded by increasing buffer sizes, ranging from $500 \mathrm{~m}$ to $2,000 \mathrm{~m}$. The food retailers are represented by black circles.

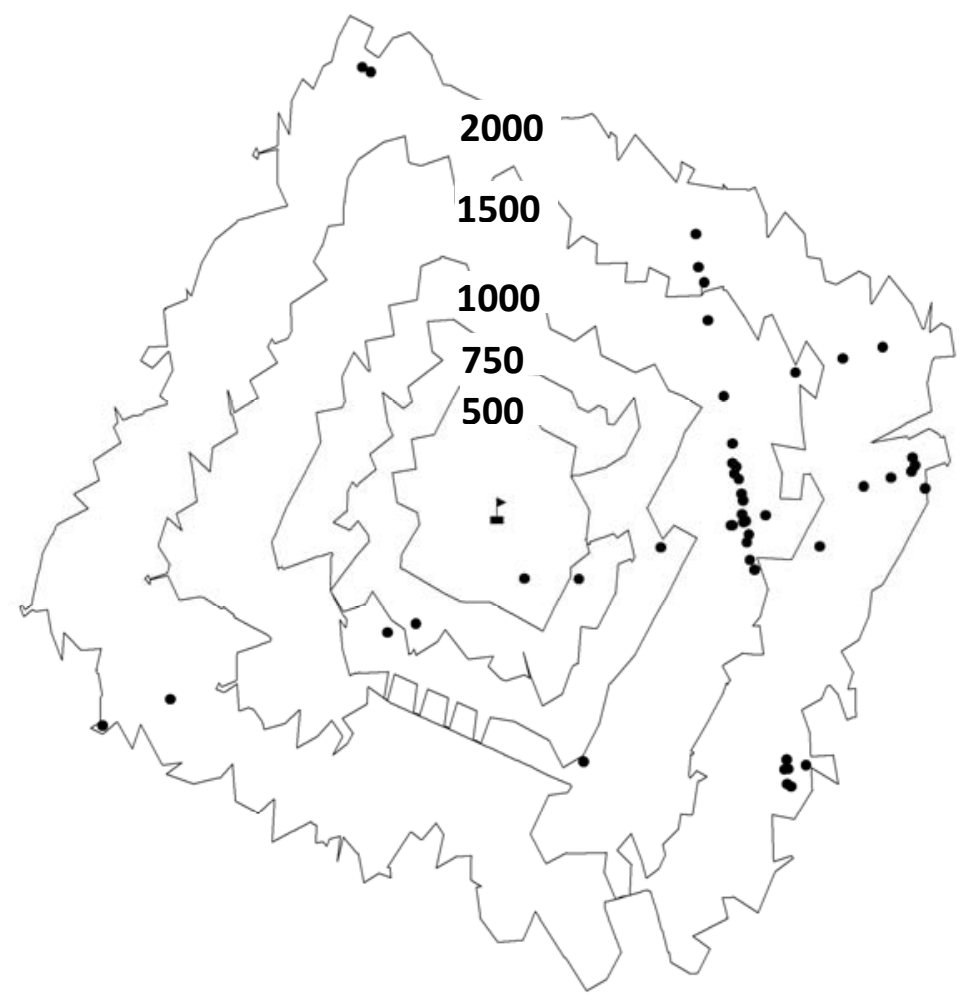

Convenience stores, fast food restaurants, and coffee/donut shops were used to develop the primary independent variable of interest. These food retailers directly corresponded to the lunchtime eating question used to create the study outcome. Addresses of these food retailers were obtained using an online Yellow Pages directory (www.yellowpages.ca). The Yellow Pages directory was chosen because it provided the most accurate information available on food retailer locations [29]. School addresses were entered into the Yellow Pages directory. The search term 'convenience stores' was used to obtain convenience store addresses. There was no single search term to use for fast food restaurants and coffee/donut shops because many of them were listed under the full service restaurant category. Therefore, we searched for the top chain food retailers, as has been done in previous studies [28,30]. The top $75 \%$ of 200 chain food retailers in Canada in 2009 were obtained from Technomic Inc. [31], and are available from the authors upon request.

All food retailers within the road network buffers were mapped using ArcGIS software. The mapping procedure in ArcGIS provided a score evaluating the accuracy of each mapped location. For food retailers whose street addresses had a score of less than $80 \%$, the Street View tool in Google Earth (C2011 Google) was used to confirm the location and obtain latitude and longitude coordinates to map them manually in ArcGIS. Because the number of food retailers within the buffers was positively skewed, they were categorized into groups. All categories were based on thresholds established for the $500 \mathrm{~m}$ network buffer size. At this distance, 74\% of schools had no nearby food retailers (categorized as "none"), and the remaining 26\% were categorized as having "1 or more" food retailers. For the remaining buffer sizes, a "none" category was created, and a threshold of the top $\sim 26 \%$ was used to denote the category with the highest number of food retailers. The thresholds for the 
remaining categories were created to ensure an approximately even distribution of schools across the categories and similar sizes among the categories.

\subsection{Lunchtime Eating Outcome}

The outcome of this study was obtained from the response to the following question: "Where do you usually eat your lunch or mid-day meal on school days?" Students who chose the response "snack-bar, fast food restaurant, café" were considered to regularly purchase their lunch from food retailers. Those who chose the remaining responses ("at school", "at home", "at someone else's house", "do not eat lunch/mid-day meal", or "other") were classified as those who did not typically obtain their lunch from food retailers.

\subsection{Confounders}

Individual-level variables, including age, sex, and socioeconomic status were considered as potential confounders since fast food consumption varies by these characteristics [6,32,33]. To obtain information on socioeconomic status, the HBSC uses the previously validated family affluence scale (FAS) [34]. Because cafeterias, vending machines, and school snack shops are associated with students' eating behaviours [35-37], they were considered as potential school-level confounders. The distance between students' homes and schools was not included as a confounder because it was not related to the study outcome with a subsample of urban youth who reported their postal code in the survey (data not shown).

\subsection{Analysis}

All analyses were conducted using SAS statistical software, version 9.2 (SAS Institute, Cary, NC, USA). Multilevel logistic regression was carried out to examine the relationship between the presence of food retailers near schools (convenience stores, fast food restaurants, and coffee/donut shops) and the likelihood of students eating their lunch at these food retailers using different sized road network buffers. For each buffer size, the multivariate model building process began with the introduction of the individual-level confounders and proceeded using a backwards elimination approach. Next, the school-level food exposure variables were forced into the model because we were interested in accounting for food sources within school as well as those surrounding schools.

The Akaike information criterion (AIC), which is a measure of goodness-of-fit when comparing two or more regression models, was determined for the final multivariate models. A difference in AIC values of between 2 to 7 indicates a moderate difference in fit of the models, while a difference of 7 or more indicates a large difference in model fit [38]. Using the difference in AIC values compared to the lowest AIC value, the relative likelihoods were determined. Next, the Akaike's weight was calculated for each model, which is the relative likelihood for each model divided by the total relative likelihood for all candidate models, and is expressed as a percentage. This percentage indicates the probability that a regression model is the best choice among a set of candidate models based on model fit [38] 


\section{Results}

The median number of student respondents per school was 37 (interquartile range: 23-55). Table 1 shows the school- and student-level characteristics. Nearly $40 \%$ of the schools were located in large metropolitan centres and $59.5 \%$ were secondary schools. There was an approximately equal distribution of males and females and only $8.0 \%$ of the study sample was in the lowest family affluence group. Of the respondents who self-reported their height and weight, 19.6\% were overweight or obese according to the International Obesity Task Force body mass index criteria [39]. Two thirds of the sample typically ate their lunch at school, 15.2\% typically ate their lunch at home, and 7.4\% typically ate their lunch in a snack bar, fast food restaurant, or cafe. Over three quarters of the schools had a cafeteria, and nearly two thirds had vending machines selling sugared drinks. Less than half of the schools had vending machines that sold milk or candy and potato chips, while less than a third had a tuck shop/snack bar.

Table 1. Characteristics of the school sample from the 2009/2010 HBSC.

\begin{tabular}{|c|c|c|}
\hline & $\mathbf{N}$ & $\%$ \\
\hline \multicolumn{3}{|l|}{ School-level variables } \\
\hline \multicolumn{3}{|l|}{ School type } \\
\hline Secondary (grades 9-12) & 94 & 59.5 \\
\hline Mixed & 64 & 40.5 \\
\hline \multicolumn{3}{|l|}{ Urban rural status } \\
\hline Large urban centre $(\geq 100,000$ people $)$ & 62 & 39.2 \\
\hline Medium urban centre $(20,000-99,999)$ & 15 & 9.5 \\
\hline Small urban centre $(1,000-19,000)$ & 38 & 24.1 \\
\hline Rural $(<1,000)$ & 43 & 27.2 \\
\hline \multicolumn{3}{|l|}{ Food Sources within Schools } \\
\hline Cafeteria & 120 & 76.0 \\
\hline Sugared drinks vending machines & 97 & 61.4 \\
\hline Milk vending machines & 75 & 47.5 \\
\hline Candy and potato chip vending machines & 64 & 40.5 \\
\hline School tuck shop/snack-bar & 51 & 32.3 \\
\hline \multicolumn{3}{|l|}{ Individual-level variables } \\
\hline \multicolumn{3}{|l|}{ Sex } \\
\hline Male & 3,381 & 48.5 \\
\hline Female & 3,590 & 51.5 \\
\hline \multicolumn{3}{|l|}{ Age (years) } \\
\hline 13 & 33 & 0.5 \\
\hline 14 & 2,339 & 33.6 \\
\hline 15 & 3,280 & 47.1 \\
\hline$\geq 16$ & 1,319 & 18.9 \\
\hline \multicolumn{3}{|l|}{ Family affluence scale } \\
\hline Low & 560 & 8.0 \\
\hline Moderate & 2,531 & 36.3 \\
\hline High & 3,880 & 55.7 \\
\hline
\end{tabular}


Table 1. Cont.

\begin{tabular}{lcc}
\hline & $\mathbf{N}$ & $\mathbf{\%}$ \\
\hline Where students eat mid-day meal & & \\
At school & 4,719 & 67.7 \\
At home & 1,056 & 15.2 \\
In a snack bar, fast food restaurant or café & 517 & 7.4 \\
Never eat a midday meal & 307 & 4.4 \\
Somewhere else & 209 & 3.0 \\
At someone else's home & 163 & 2.3 \\
Weight status & & \\
Non-overweight & 4,823 & 69.2 \\
Overweight & 1,018 & 14.6 \\
Obese & 346 & 5.0 \\
Missing data & 784 & 11.3 \\
\hline
\end{tabular}

Table 2 provides the quantity of food retailers within the various buffer sizes. Very few food retailers were obtained within the smallest buffers; only 88 food retailers were located within $500 \mathrm{~m}$ buffers for the 158 schools in this study. The median number of food retailers ranged from 0 to 13 across the buffer sizes, and median values were greater than zero for buffers of 1,000 $\mathrm{m}$ and larger.

Table 2. The distribution of food retailers within the various buffer sizes.

\begin{tabular}{cccccc}
\hline Buffer size & $\begin{array}{c}\text { Total number of } \\
\text { food retailers }\end{array}$ & $\begin{array}{c}\text { 25th } \\
\text { Percentile }\end{array}$ & $\begin{array}{c}\text { 50th } \\
\text { Percentile }\end{array}$ & $\begin{array}{c}\text { 75th } \\
\text { Percentile }\end{array}$ & Maximum \\
\hline $500 \mathrm{~m}$ & 88 & 0 & 0 & 1 & 7 \\
$750 \mathrm{~m}$ & 193 & 0 & 0 & 2 & 9 \\
$1,000 \mathrm{~m}$ & 349 & 0 & 1 & 3 & 15 \\
$1,500 \mathrm{~m}$ & 768 & 0 & 3 & 7 & 27 \\
$2,000 \mathrm{~m}$ & 1,279 & 1 & 6 & 12 & 53 \\
$5,000 \mathrm{~m}$ & 4,798 & 1 & 13 & 43 & 275 \\
\hline
\end{tabular}

Results of the multilevel logistic regression are shown in Table 3. Model 1 shows the bivariate relationships, Model 2 controlled for individual-level covariates, and Model 3 controlled for individual- and school-level covariates. The strongest relationship appeared to be for the $1,000 \mathrm{~m}$ buffer, where students who had 3 or more food retailers within $1,000 \mathrm{~m}$ of their schools had 3.42 (95\% CI: 2.12-5.52) times the relative odds of eating lunch at a food retailer compared to students with no food retailers within $1,000 \mathrm{~m}$. The smallest two buffer sizes also showed relationships with lunchtime eating behaviours. At buffer sizes greater than $1,000 \mathrm{~m}$, these relationships were weaker and not statistically significant (exceptions: $7-10$ and 11 or more food retailers for the 2,000 m buffer).

The AIC-related values comparing goodness-of-fit between the final regression models (Model 3 in Table 3) for the different buffer sizes are shown in Table 4. The 1,000 $\mathrm{m}$ buffer had the lowest AIC value. The difference in AIC values between the 1,000 $\mathrm{m}$ buffer model and all remaining models was greater than the threshold value of 7 , which indicated that there was a substantially better model fit for 
the 1,000 m buffer. Results from the Akaike's weights showed there was a $98.8 \%$ probability that the $1,000 \mathrm{~m}$ road network buffer provided the best fit among the candidate models.

Table 3. Food retail buffer size and eating lunch at a snack-bar, fast food restaurant, or café.

\begin{tabular}{|c|c|c|c|c|}
\hline \multirow{2}{*}{$\begin{array}{l}\text { Number of food } \\
\text { retailers within buffer }\end{array}$} & \multirow{2}{*}{$\begin{array}{l}\text { Number of } \\
\text { schools (\%) }\end{array}$} & \multicolumn{3}{|c|}{ Odds ratio ( $95 \%$ confidence interval) } \\
\hline & & Model 1 & Model 2 & Model 3 \\
\hline \multicolumn{5}{|l|}{$500 \mathrm{~m}$} \\
\hline None & $117(74.1)$ & 1.00 & 1.00 & 1.00 \\
\hline 1 or more & $41(25.9)$ & $2.15(1.38-3.36)$ & $2.20(1.40-3.46)$ & $2.27(1.46-3.52)$ \\
\hline \multicolumn{5}{|l|}{$750 \mathrm{~m}$} \\
\hline None & $89(56.3)$ & 1.00 & 1.00 & 1.00 \\
\hline 1 & $26(16.5)$ & $1.44(0.82-2.54)$ & $1.50(0.84-2.66)$ & $1.40(0.79-2.48)$ \\
\hline 2 or more & $43(27.2)$ & $2.84(1.81-4.47)$ & $2.90(1.83-4.60)$ & $2.74(1.75-4.29)$ \\
\hline \multicolumn{5}{|l|}{$1,000 \mathrm{~m}$} \\
\hline None & $62(39.2)$ & 1.00 & 1.00 & 1.00 \\
\hline $1-2$ & $51(32.3)$ & $1.24(0.76-2.02)$ & $1.25(0.76-2.06)$ & $1.20(0.74-1.95)$ \\
\hline 3 or more & $45(28.4)$ & $3.49(2.17-5.61)$ & $3.55(2.19-5.76)$ & $3.42(2.12-5.52)$ \\
\hline \multicolumn{5}{|l|}{$1,500 \mathrm{~m}$} \\
\hline None & $43(27.2)$ & 1.00 & 1.00 & 1.00 \\
\hline $1-2$ & $25(15.8)$ & $1.21(0.60-2.45)$ & $1.20(0.59-2.45)$ & $1.22(0.59-2.53)$ \\
\hline $3-4$ & $20(12.7)$ & $1.45(0.71-2.97)$ & $1.43(0.69-2.97)$ & $1.37(0.66-2.88)$ \\
\hline $5-6$ & $26(16.5)$ & $1.88(0.97-3.64)$ & $1.91(0.98-3.74)$ & $1.85(0.94-3.65)$ \\
\hline 7 or more & $44(27.8)$ & $3.06(1.72-5.44)$ & $3.13(1.75-5.62)$ & $2.96(0.64-5.34)$ \\
\hline \multicolumn{5}{|l|}{$2,000 \mathrm{~m}$} \\
\hline None & $34(21.5)$ & 1.00 & 1.00 & 1.00 \\
\hline $1-3$ & $28(17.7)$ & $1.34(0.64-2.83)$ & $1.32(0.62-2.82)$ & $1.38(0.65-2.96)$ \\
\hline $4-6$ & $25(15.8)$ & $1.50(0.71-3.19)$ & $1.54(0.72-3.30)$ & $1.50(0.67-3.34)$ \\
\hline $7-10$ & $22(13.9)$ & $2.37(1.16-4.87)$ & $2.43(1.17-5.04)$ & $2.28(1.07-4.86)$ \\
\hline 11 or more & $45(28.5)$ & $2.56(1.33-4.93)$ & $2.57(1.32-5.02)$ & $2.48(1.23-5.02)$ \\
\hline \multicolumn{5}{|l|}{$5,000 \mathrm{~m}$} \\
\hline None & $30(19.0)$ & 1.00 & 1.00 & 1.00 \\
\hline $1-9$ & $35(22.2)$ & $1.39(0.65-2.95)$ & $1.38(0.64-2.96)$ & $1.26(0.58-2.77)$ \\
\hline $11-19$ & $31(19.6)$ & $1.65(0.77-3.51)$ & $1.69(0.78-2.65)$ & $1.48(0.66-3.33)$ \\
\hline $20-29$ & $11(7.0)$ & $2.04(0.75-5.57)$ & $2.01(0.72-5.57)$ & $1.94(0.67-5.61)$ \\
\hline $30-39$ & $11(7.0)$ & $2.22(0.82-6.00)$ & $2.18(0.79-6.01)$ & $1.95(0.70-5.45)$ \\
\hline 40 or more & $40(25.3)$ & $2.09(1.02-4.29)$ & $2.11(1.02-4.38)$ & $1.81(0.83-3.97)$ \\
\hline
\end{tabular}

\section{Discussion}

This study identified the 1,000 $\mathrm{m}$ road network buffer as the appropriate buffer size for examining the relationship between the school food retail environment and lunchtime eating behaviours. Based upon an average walking speed of 4-5 km/hour in adolescents [40], this is a distance that could be walked in approximately 10-15 minutes. At distances less than $1,000 \mathrm{~m}$, less than half of the schools had at least one food retailer present, suggesting these buffers were too small to capture a sufficient 
number of food retailers. Distances greater than 1,000 m may be perceived by students as being too far for them to travel during the time allotted for their lunch break. In Canada, lunch breaks at school typically range from 30 minutes to 1 hour in length, with most lasting about 45 minutes. If it takes 10 minutes to walk $1 \mathrm{~km}$, there would be sufficient time to purchase and eat lunch at a fast food or convenience retailer located within $1,000 \mathrm{~m}$ of schools.

Table 4. Comparison of AIC values, relative likelihoods, and Akaike's weights across various buffer sizes.

\begin{tabular}{ccccc}
\hline Buffer size & AIC value & $\boldsymbol{\Delta}$ AIC vs. 1,000 m distance & $\begin{array}{c}\text { Relative likelihood } \\
\mathbf{e}^{(-\mathbf{0 . 5} \times \Delta \text { AIC })}\end{array}$ & Akaike's weight (\%) \\
\hline $500 \mathrm{~m}$ & $3,356.64$ & 12.77 & 0.00169 & 0.167 \\
$750 \mathrm{~m}$ & $3,353.12$ & 9.25 & 0.00980 & 0.969 \\
$1,000 \mathrm{~m}$ & $3,343.87$ & 0 & 1.00000 & 98.836 \\
$1,500 \mathrm{~m}$ & $3,360.21$ & 16.34 & 0.00028 & 0.028 \\
$2,000 \mathrm{~m}$ & $3,366.72$ & 22.85 & 0.00001 & 0.000 \\
$5,000 \mathrm{~m}$ & $3,373.94$ & 30.07 & 0.00000 & 0.000 \\
Total & & & 1.01178 & 100.00 \\
\hline
\end{tabular}

The association between the number of food retailers within $500 \mathrm{~m}, 750 \mathrm{~m}$, and 1,000 $\mathrm{m}$ road network buffers around schools and students' eating behaviours was consistent with observations by Davis and Carpenter [14]. They found that chain fast food restaurants within 0 to $400 \mathrm{~m}$ and $400 \mathrm{~m}$ to $800 \mathrm{~m}$ of schools were associated with students' BMI values. An advantage of our study is that it used model fit criteria to determine that the $1,000 \mathrm{~m}$ buffer size was the most appropriate. It is important to note that the most appropriate buffer size may be different for non-school settings. Studies of the food retail environment surrounding homes have provided mixed results, with two suggesting that a relatively small (i.e., 400 to $800 \mathrm{~m}$ ) buffer size may be the most appropriate [20,25], and one study suggesting that larger (i.e., 1,600 $\mathrm{m}$ ) buffer sizes are most appropriate [24].

Results from this study provide important evidence regarding the appropriate buffer size to use when measuring the food retail environment surrounding schools. Namely, using a buffer that is either too large or too small may obscure relationships with eating behaviours and result in weakened study findings. Furthermore, having a standard buffer size will enhance comparability across studies. Finally, results from studies such as this one are needed to inform the implementation and evaluation of policies aimed at optimizing the built environment surrounding schools. Specifically, our findings suggest that policies that limit the number of food retailers around schools should consider a 1,000 m distance and a maximum of 2 fast food restaurants, coffee/donut shops, and/or convenience stores. More than one quarter (28.4\%) of the schools studied here would be affected by such a policy.

This study has some key strengths including: the large and geographically diverse study sample, the wide variety of buffer sizes, and the use of goodness-of-fit statistics to assess the relative contribution of each buffer size to model fit. Another key strength of this study is that it considered constraints on mobility and time when measuring accessibility to food retailers. In other words, by limiting our study outcome to a specific time and place to eat (e.g., lunch time during the school day), we accounted for these limitations on spatial accessibility. Measures of spatial accessibility that consider limitations 
imposed by time and space are weakly correlated with those which do not consider them [41] and this has been confirmed in studies of the Canadian food environment [42]. Future studies should consider food environments and eating behaviours that are specific to them, such as the journey to and from school as well as the home environment.

A key limitation of this study was that the GIS database used to obtain information on the food environment does not provide a completely accurate measure of the food environment. Furthermore, for practical reasons, only the top chain fast food restaurants and donut/coffee retailers were included in the food retail environment measures. In addition, the survey data were obtained by self-report and this may introduce bias due to the social desirability of eating healthy foods [43]. It is also possible that students may have reported higher food intakes than what they actually consumed, since young people who have low body weights tend to over-report their energy intake [44]. Finally, the cross-sectional nature of this study made it impossible to assess temporality between the presence of food retailers and eating behaviours. However, it is unlikely that students chose to attend schools based on the presence of nearby food retailers. In fact, there is evidence to suggest that fast food restaurants cluster around schools [11], indicating that some food retailers may be preferentially located near schools.

\section{Conclusions}

The results from this study indicated that the most appropriate road network buffer distance when assessing the food retail environment surrounding Canadian schools was 1,000 m. Future studies investigating the school food retail environment should consider using street network buffers of this size. Having a consistent buffer size across studies will not only help inform policies and interventions directed at the modification of the food environment surrounding schools, but will also help facilitate comparisons across studies.

\section{Acknowledgments}

The authors of this study would like to thank Mariane Héroux, Rachel Laxer and Hoda Gharib for their assistance in the collection of the food retailer addresses. The 2009/2010 Health Behaviour in School-aged Children Study (HBSC), a World Health Organization/European Region collaborative study, was funded in Canada by the Public Health Agency of Canada and Health Canada. This study was funded by an operating grant from the Canadian Institutes of Health Research (MOP 97962), and a second operating grant co-funded by the Canadian Institutes of Health Research and the Heart and Stroke Foundation of Canada (PCR 101415). In addition, Laura Seliske was supported by a Frederick Banting and Charles Best Doctoral Research Award from the Canadian Institutes of Health Research. Ian Janssen was supported by a Canada Research Chair and an investigator award from the Ontario Ministry of Research and Innovation. The principal investigators of the 2009/2010 Canadian HBSC were John Freeman and William Pickett, and the HBSC is coordinated internationally by Candace Currie (University of Edinburgh).

\section{Conflict of Interest}

The authors declare that they have no competing interests. 


\section{References}

1. Popkin, B.M.; Gordon-Larsen, P. The nutrition transition: Worldwide obesity dynamics and their determinants. Int. J. Obes. Relat. Metab. Disord. 2004, 28, S2-S9.

2. Summerbell, C.D.; Waters, E.; Edmunds, L.D.; Kelly, S.; Brown, T.; Campbell, K.J. Interventions for preventing obesity in children. Cochrane Database Syst. Rev. 2005, doi: 10.1002/14651858. CD001871.pub2.

3. Casey, R.; Oppert, J.M.; Weber, C.; Charreire, H.; Badariotti, D.; Banos, A.; Fischler, C.; Giacoman Hernandez, C.; Chaix, B.; Simon, C. Determinants of childhood obesity: What can we learn from built environment studies? Food Qual. Prefer. 2011, doi:10.1016/j.foodqual. 2011.06.003.

4. Paeratakul, S.; Ferdinand, D.P.; Champagne, C.M.; Ryan, D.H.; Bray, G.A. Fast-food consumption among US adults and children: Dietary and nutrient intake profile. J. Am. Diet. Assoc. 2003, 103, 1332-1338.

5. Pereira, M.A.; Kartashov, A.I.; Ebbeling, C.B.; van Horn, L.; Slattery, M.L.; Jacobs, D.R., Jr.; Ludwig, D.S. Fast-food habits, weight gain, and insulin resistance (the CARDIA study): 15-year prospective analysis. Lancet 2005, 365, 36-42.

6. Bowman, S.A.; Gortmaker, S.L.; Ebbeling, C.B.; Pereira, M.A.; Ludwig, D.S. Effects of fast-food consumption on energy intake and diet quality among children in a national household survey. Pediatrics 2004, 113, 112-118.

7. Bradlee, M.L.; Singer, M.R.; Qureshi, M.M.; Moore, L.L. Food group intake and central obesity among children and adolescents in the Third National Health and Nutrition Examination Survey (NHANES III). Public Health Nutr. 2010, 13, 797-805.

8. Berkey, C.S.; Rockett, H.R.; Field, A.E.; Gillman, M.W.; Colditz, G.A. Sugar-added beverages and adolescent weight change. Obes. Res. 2004, 12, 778-788.

9. Lindquist, C.H.; Gower, B.A.; Goran, M.I. Role of dietary factors in ethnic differences in early risk of cardiovascular disease and type 2 diabetes. Am. J. Clin. Nutr. 2000, 71, 725-732.

10. Taveras, E.M.; Berkey, C.S.; Rifas-Shiman, S.L.; Ludwig, D.S.; Rockett, H.R.; Field, A.E.; Colditz, G.A.; Gillman, M.W. Association of consumption of fried food away from home with body mass index and diet quality in older children and adolescents. Pediatrics 2005, 116, e518-e524.

11. Austin, S.B.; Melly, S.J.; Sanchez, B.N.; Patel, A.; Buka, S.; Gortmaker, S.L. Clustering of fast-food restaurants around schools: A novel application of spatial statistics to the study of food environments. Am. J. Public Health 2005, 95, 1575-1581.

12. Day, P.L.; Pearce, J. Obesity-promoting food environments and the spatial clustering of food outlets around schools. Am. J. Prev. Med. 2011, 40, 113-121.

13. Seliske, L. The Built Environment and Obesity-Related Behaviours in Canadian Youth. PhD Thesis, Queen's University, Kingston, ON, Canada, 2012.

14. Davis, B.; Carpenter, C. Proximity of fast-food restaurants to schools and adolescent obesity. Am. J. Public Health 2009, 99, 505-510. 
15. Howard, P.H.; Fitzpatrick, M.; Fulfrost, B. Proximity of food retailers to schools and rates of overweight ninth grade students: An ecological study in California. BMC Public Health 2011, doi:10.1186/1471-2458-11-68.

16. Powell, L.M.; Auld, M.C.; Chaloupka, F.J.; O’Malley, P.M.; Johnston, L.D. Associations between access to food stores and adolescent body mass index. Am. J. Prev. Med. 2007, 33, S301-S307.

17. Casey, A.A.; Elliott, M.; Glanz, K.; Haire-Joshu, D.; Lovegreen, S.L.; Saelens, B.E.; Sallis, J.F.; Brownson, R.C. Impact of the food environment and physical activity environment on behaviors and weight status in rural U.S. communities. Prev. Med. 2008, 47, 600-604.

18. Inagami, S.; Cohen, D.A.; Finch, B.K.; Asch, S.M. You are where you shop: Grocery store locations, weight, and neighborhoods. Am. J. Prev. Med. 2006, 31, 10-17.

19. Leatherdale, S.T.; Pouliou, T.; Church, D.; Hobin, E. The association between overweight and opportunity structures in the built environment: A multi-level analysis among elementary school youth in the PLAY-ON study. Int. J. Public Health 2011, 56, 237-246.

20. Leung, C.W.; Laraia, B.A.; Kelly, M.; Nickleach, D.; Adler, N.E.; Kushi, L.H.; Yen, I.H. The influence of neighborhood food stores on change in young girls' body mass index. Am. J. Prev. Med. 2011, 41, 43-51.

21. Williams, L.K.; Thornton, L.; Ball, K.; Crawford, D. Is the objective food environment associated with perceptions of the food environment? Public Health Nutr. 2011, 15, 291-298.

22. Fraser, L.K.; Edwards, K.L. The association between the geography of fast food outlets and childhood obesity rates in Leeds, UK. Health Place 2010, 16, 1124-1128.

23. Fleischhacker, S.E.; Evenson, K.R.; Rodriguez, D.A.; Ammerman, A.S. A systematic review of fast food access studies. Obes. Rev. 2011, 12, e460-e471.

24. Laska, M.N.; Hearst, M.O.; Forsyth, A.; Pasch, K.E.; Lytle, L. Neighbourhood food environments: Are they associated with adolescent dietary intake, food purchases and weight status? Public Health Nutr. 2010, 13, 1757-1763.

25. Spence, J.C.; Cutumisu, N.; Edwards, J.; Raine, K.D.; Smoyer-Tomic, K. Relation between local food environments and obesity among adults. BMC Public Health 2009, 9, doi:10.1186/ 1471-2458-9-192.

26. Jennings, A.; Welch, A.; Jones, A.P.; Harrison, F.; Bentham, G.; van Sluijs, E.M.; Griffin, S.J.; Cassidy, A. Local food outlets, weight status, and dietary intake: Associations in children aged 9-10 years. Am. J. Prev. Med. 2011, 40, 405-410.

27. Seliske, L.M.; Pickett, W.; Boyce, W.F.; Janssen, I. Association between the food retail environment surrounding schools and overweight in Canadian youth. Public Health Nutr. 2009, 12, 1384-1391.

28. Crawford, D.A.; Timperio, A.F.; Salmon, J.A.; Baur, L.; Giles-Corti, B.; Roberts, R.J.; Jackson, M.L.; Andrianopoulos, N.; Ball, K. Neighbourhood fast food outlets and obesity in children and adults: The CLAN Study. Int. J. Pediatr. Obes. 2008, 3, 249-256.

29. Seliske, L.M.; Pickett, W.; Bates, R.; Janssen, I. Field validation of food service listings: A comparison of commercial and online geographic information system databases. 2012, 9, 2601-2607.

30. Alter, D.A.; Eny, K. The relationship between the supply of fast-food chains and cardiovascular outcomes. Can. J. Public Health 2005, 96, 173-177. 
31. Technomic. Top 200 Canadian Chain Restaurant Report; Technomic Inc.: Chicago, IL, USA, 2010.

32. French, S.A.; Story, M.; Neumark-Sztainer, D.; Fulkerson, J.A.; Hannan, P. Fast food restaurant use among adolescents: Associations with nutrient intake, food choices and behavioral and psychosocial variables. Int. J. Obes. Relat. Metab. Disord. 2001, 25, 1823-1833.

33. Campbell, K.; Crawford, D.; Jackson, M.; Cashel, K.; Worsley, A.; Gibbons, K.; Birch, L.L. Family food environments of 5-6-year-old-children: Does socioeconomic status make a difference? Asia Pac. J. Clin. Nutr. 2002, 11, S553-S561.

34. Currie, C.; Molcho, M.; Boyce, W.; Holstein, B.; Torsheim, T.; Richter, M. Researching health inequalities in adolescents: The development of the health behaviour in school-aged children (HBSC) family affluence scale. Soc. Sci. Med. 2008, 66, 1429-1436.

35. Briefel, R.R.; Crepinsek, M.K.; Cabili, C.; Wilson, A.; Gleason, P.M. School food environments and practices affect dietary behaviors of US public school children. J. Am. Diet. Assoc. 2009, 109, S91-S107.

36. Kubik, M.Y.; Lytle, L.A.; Hannan, P.J.; Perry, C.L.; Story, M. The association of the school food environment with dietary behaviors of young adolescents. Am. J. Public Health 2003, 93, 1168-1173.

37. Park, S.; Sappenfield, W.M.; Huang, Y.; Sherry, B.; Bensyl, D.M. The impact of the availability of school vending machines on eating behavior during lunch: The youth physical activity and nutrition survey. J. Am. Diet. Assoc. 2010, 110, 1532-1536.

38. Burnham, K.P.; Andersen, L.B. Model Selection and Multimodel Inference: A Practical Information-Theoretic Approach; Springer: New York, NY, USA, 2002.

39. Cole, T.J.; Bellizzi, M.C.; Flegal, K.M.; Dietz, W.H. Establishing a standard definition for child overweight and obesity worldwide: International survey. BMJ 2000, 320, 1240-1243.

40. Oberg, T.; Karsznia, A.; Oberg, K. Basic gait parameters: Reference data for normal subjects, 10-79 years of age. J. Rehabil. Res. Dev. 1993, 30, 210-223.

41. Kwan, M.P. Space-time and integral measures of individual accessibility: A comparative analysis using a point-based framework. Geogr. Anal. 1998, 30, 191-216.

42. Kestens, Y.; Lebel, A.; Daniel, M.; Theriault, M.; Pampalon, R. Using experienced activity spaces to measure foodscape exposure. Health Place 2010, 16, 1094-1103.

43. Klesges, L.M.; Baranowski, T.; Beech, B.; Cullen, K.; Murray, D.M.; Rochon, J.; Pratt, C. Social desirability bias in self-reported dietary, physical activity and weight concerns measures in 8 to 10 year-old African-American girls: Results from the girls health enrichment multisite studies (GEMS). Prev. Med. 2004, 38, S78-S87.

44. Vagstrand, K.; Lindroos, A.K.; Linne, Y. Characteristics of high and low energy reporting teenagers and their relationship to low energy reporting mothers. Public Health Nutr. 2009, 12, 188-196.

(C) 2012 by the authors; licensee MDPI, Basel, Switzerland. This article is an open access article distributed under the terms and conditions of the Creative Commons Attribution license (http://creativecommons.org/licenses/by/3.0/). 